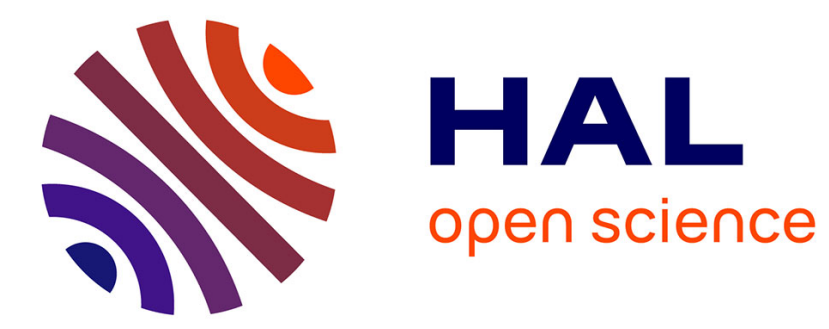

\title{
Imperceptible Art
}

Aleksandra Vasovic

\section{To cite this version:}

Aleksandra Vasovic. Imperceptible Art. 17th International Conference on Entertainment Computing (ICEC), Sep 2018, Poznan, Poland. pp.337-339, 10.1007/978-3-319-99426-0_40 . hal-02128605

\section{HAL Id: hal-02128605 \\ https://inria.hal.science/hal-02128605}

Submitted on 14 May 2019

HAL is a multi-disciplinary open access archive for the deposit and dissemination of scientific research documents, whether they are published or not. The documents may come from teaching and research institutions in France or abroad, or from public or private research centers
L'archive ouverte pluridisciplinaire HAL, est destinée au dépôt et à la diffusion de documents scientifiques de niveau recherche, publiés ou non, émanant des établissements d'enseignement et de recherche français ou étrangers, des laboratoires publics ou privés. 


\title{
Imperceptible Art
}

\author{
Aleksandra Vasovic ${ }^{1}$ \\ ${ }^{1}$ Independent Artist, Alekse Nenadovica 5, 11000 Belgrade, Serbia Princeton \\ a.s.vasovicegmail.com
}

\begin{abstract}
The paper is text based artwork, a part of the ongoing project, work in progress, contemporary digital art live performance and it is contemplating about the idea to what extent could the process of employment of the instruments (which are assisting the visualization procedures within the field of visual and contemporary art, like augmented reality or virtual reality tools) - evolve.
\end{abstract}

Keywords: Augmented Reality, Virtual Reality, Artificial Intelligence, Digital Live Performance, Contemporary Art, Text Based Artwork, Philosophy, Spirituality.

\section{Introduction}

\subsection{The Context - in the Art. The Objectives - in the Art}

The text-based artwork, situated within the practice of contemporary art and media art, is contemplating and thinking artistically in which ways is possible to expand, refer to and explore, via the mechanisms of art, the philosophical and spiritual approach - that the visible or perceptual reality does not exist and is merely an abstract concept.

The goal is to be comprehended inside the context of art - because of the specific nature of the "goal" when applied to the art and artistic activities. It is not mandatory and generally not possible to propose the goals when attempting to undertake or be involved in the artistic process, or to actualize the final artistic outcome or product. Accordingly, the artistic process and action itself is a goal, and it coincides with the spiritual thesis, which is also included in the artistic project: the witnessing or observing the unfolding of some process is some kind of a goal. Even though in transcendental terms, any goal can be defined as abstract concept, beyond any practical potential and implementation, it is exciting to examine what would visualization instruments, like augmented reality or virtual reality devices, in fact visualize, in the situations when there is nothing at all to be visualized. Or more precisely, when there is nothing more left except for the unadulterated substance within the contexts of art, philosophy or spirituality. 


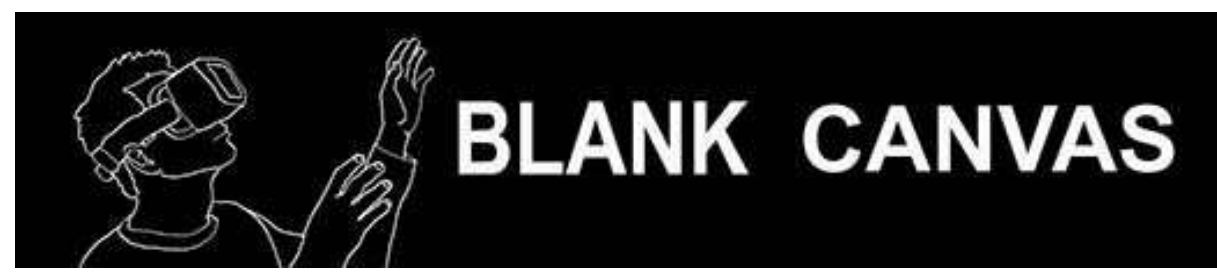

Fig. 1. Imperceptible Art - drafts

. Video: https://youtu.be/AIcaOGzb1I4

\section{Description}

\subsection{A Prefered Methodology and Potential Outcome}

The artwork, a part of the artistic installation, consists of several variations, which not only are the constitutive elements of the artistic process, but also are independent, autonomous, and sustainable to maintain as separate individual artworks.

The initial part of the artwork is text-based; there would be other stages, e.g. art installations and performances.

In a suitable exhibiting space, maybe at the conference venue, some augmented reality (AR) or virtual reality (VR) tools and technology, would be applied.

Art installation or artwork consists of:

- VR headset, EEG neuroheadset and custom made software (running on PC). Brain activity is presented by computer generated virtual environment that responds to brain activity in real time. Hardware integration, software development (and implementation directly at the exhibiting space/conference venue) is provided by a team of developers specializing in virtual reality applications since 2005.

- The public, which interacts with the technology and continues to co-create artwork, which is in this way expanding by creating random outcome which is to be documented and evaluated - both from the artistic (and perhaps) scientific aspect in consequent stages of the ongoing project.

- The interaction between the technology and the public is generating the live performance, which is then developing further when shared via social networks and the internet, in which way the live performance alters from the on the spot event to the ongoing ubiquitous ever-expanding situation and experience, which absorbs certain characteristics existing within the context of the theater.

The procedure: the public, the audience, would apply the tool and create whatever is the product of their mental content, thoughts, imagination, emotions, whatever illustrates the mental and cognitive process.

As the project evolves, the meditations and prayers, or other applicable techniques will be introduced to the process and the VR tools would be used for creating the visualizations of the altered process. However, it is crucial that the art audience also consists of some individuals who perform meditation techniques, or prayers, or any other advanced spiritual methods and practice. It would be desirable, in subsequent 
stages, if the machines, which are creating artistic works using artificial intelligence, were also be incorporated in both personifications - as art public and as co-authors within this project. The results or visualizations would also be recorded.

The next phase is to use the VR tool to attempt to visualize or bring to life the content which is thought-less, and which is gained in the most advanced phases of spiritual practice - or even better, spontaneously, without the spiritual practice, which is in this case the preferred alternation compared to implementation of any proscribed technique or method, spiritual or not spiritual. When there are no thoughts, ideas and concepts to be seen or observed, detected, what is the resultant - would be interesting to record.

This final and most advanced phase for some participants will be reached and executed within nanoseconds, for some within years, for most within decades and even longer... it is a

regular routine, as this live performance is ongoing, work in progress [1].

The other part of this artistic experiment would be recording activity and defining what is the significance of the recording and documenting when there is no detectable essence to document.

\section{Conclusions}

\subsection{Art, Life, Entertainment}

In such an extensive and dispersed territory like contemporary art, the safe conclusion is that the consistent artistic practice to never stop arising questions remains the very foundation of the discipline [2].

If art live performance succeeds to record that there is nothing to be recorded in the final phases of the live performance, then it is obvious to point to whom and why will it be relevant to evaluate the recordings? Is the artist, the author, authorized to evaluate them more than the artwork's co-creators; or is some distant observer, who is observing the progress of the performance, accredited to do so - is yet to be defined, if possible [3].

Another conclusion might be that (although there is no perceivable substance to be recorded and there is no one, no real person, as metaphysics or some branches of philosophy indicate, who could take the documentation into consideration), the process in its entirety and complexity was entertaining, that art is entertaining discipline and this is the sufficient and valuable reason for the procedure to be performed.

Maybe the entertainment is also the reas on valid enough for the entire idea perceived as reality (in spiritual and philosophical context) to occur [4].

\section{References}

1. Swami, V.: The Concise Yoga Vasistha. In: Page 5 Hinduism, philosophical script, Advaita Vedanta. State University of New York, Albany (1984)

2. Smith, T.: What is Contemporary Art? Chicago: University of Chicago Press (2009) 
3. Chandler, L.: Science and Buddhism Agree: There Is No "You" There. In: http://bigthink.com/ideafeed/good-news-science-buddha-agree-theres-noyou?utm_campaign=Echobox\&utm_medium $=$ Social\&utm_source $=$ Facebook\#link_time $=1$ 495747728K. bigthink.com (2016)

4. Vedral, V.: Decoding Reality. Oxford University Press, (2012) 